\title{
A RELAÇÃO ENTRE OCUPAÇÃO DO RELEVO E OS EPISÓDIOS DE ALAGAMENTOS NA CIDADE DE CAPINÓPOLIS/MG
}

\author{
Húrbio Rodrigues de Oliveira Costa ${ }^{(a)}$ Leda Correia Pedro Miyazaki ${ }^{(b)}$
}

(a) Aluno do Programa de Pós - Graduação em Geografia do Pontal/ Faculdade de Ciências Integradas do Pontal (FACIP), Universidade Federal de Uberlândia (UFU), hurbiorodrigues@ gmail.com

(b) Profa. do Curso de Graduação e do Programa de Pós - Graduação em Geografia do Pontal/ Faculdade de Ciências Integradas do Pontal (FACIP), Universidade Federal de Uberlândia (UFU), lecpgeo@ gmail.com

\section{Eixo: GEOGRAFIA FISICA E DESASTRES NATURAIS}

\begin{abstract}
Resumo/
O objetivo deste trabalho foi analisar a relação entre a ocupação do relevo e os episódios de alagamentos que ocorrem na cidade de Capinópolis/MG. Os alagamentos vêm se tornando cada dia mais comuns nas cidades, fato explicado pelas diversas alterações provocadas na paisagem durante $o$ processo de ocupação do relevo. Assim, foram utilizados como procedimentos metodológicos revisão bibliográfica, reportagens dos principais meios de comunicação da cidade, dados do Instituto Nacional de Meteorologia, informações referentes a precipitação mensal e os eventos ocorridos num dado mês. A partir daí foi possível estabelecer uma relação entre os eventos, os dados de precipitação e o processo de ocupação do relevo na área urbana do município de Capinópolis/MG, os eventos ocorridos se relacionam diretamente com os dias em que houve maior precipitação, no entanto não é o fator predominante, pois o processo de ocupação contribuiu efetivamente para a ocorrência destes eventos.
\end{abstract}

Palavras chave: alagamentos; precipitação; ocupação; relevo.

\section{Introdução}

Eventos relacionados às dinâmicas pluviais vêm ganhando espaço na mídia seja por conta dos impactos causados na vida daqueles que foram atingidos, ou ainda pela sua origem, o que normalmente coincide com alterações realizadas pelo homem durante o processo de apropriação e ocupação do relevo. Vertentes passam a ser impermeabilizadas e suas formas originais alteradas, durante o processo de ocupação do relevo as vertentes passam a serem impermeabilizadas, as áreas de fundos de vale tendem a serem ocupadas por residênciais, avenidas entre outras infraestruturas impostas pela dinâmica urbana. Essas intervenções rompem o equilibrio dinâmico dos processos naturais, o que acaba provocando uma série de impactos como os alagamentos, erosões, solapamento de margens de córregos, assoreamento do canal fluvial, movimentos de massa em áreas de encosta, entre outros. Pensando-se neste quadro que envolve a ocupação do relevo e o rompimento do equilibrio dinâmico dos processos naturais que está provocando a 


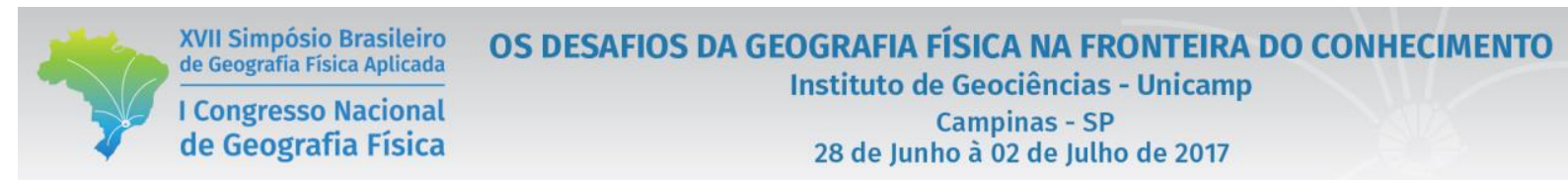

ocorrência dos alagamentos, optou-se em estudar alguns casos ocorridos na área urbana do município de Capinópolis/MG.

O município de Capinópolis se localiza na Mesorregião do Triângulo Mineiro/Alto Paranaíba e Microrregião Geográfica de Ituiutaba (figura 1), cujas coordenadas geográficas são $18^{\circ} 40^{\prime} 55^{\prime}$ ' $\mathrm{S}$ e 49³4'12' W. O município possui altitude máxima de 786 metros e mínima de 420 metros, tendo como principais corpos d'água Rio Paranaíba, Ribeirão das Três Barras, Ribeirão do Queixada, Córrego do Capim e Córrego Olaria (PREFEITURA MUNICIPAL DE CAPINÓPOLIS, 2014).
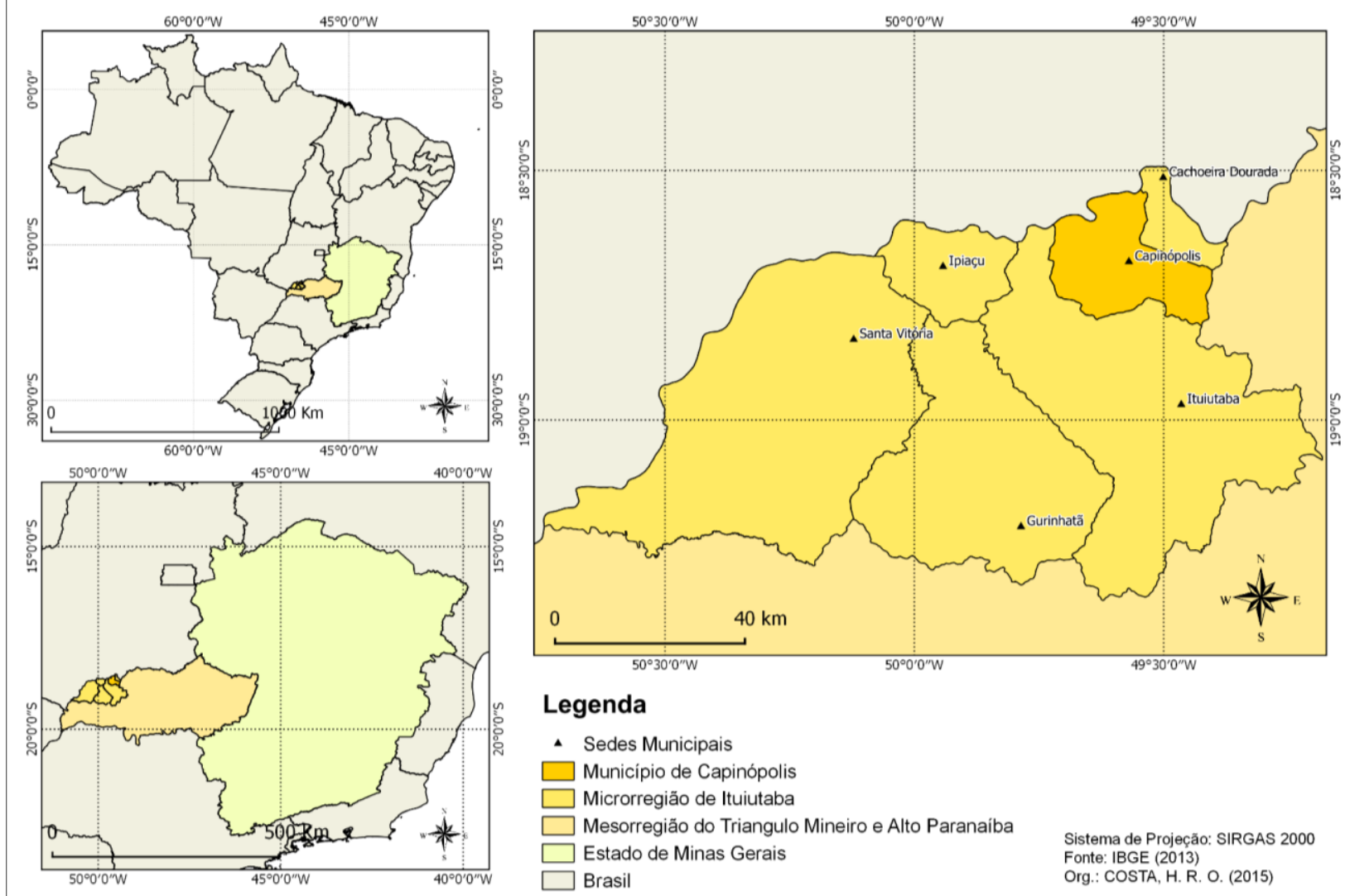

Figura 01: Localização do município de Capinópolis/ MG.

A presença de canais fluviais na área urbana do município de Capinópolis/MG faz com que os impactos nas vertentes e áreas de fundo de vale, tornem-se ainda mais evidentes, a partir daí optou-se por definir como área de estudo a bacia do córrego Olaria, sendo esta uma das áreas mais afetadas pela expansão territorial urbana. Essa expansão teve seu início às margens de outro córrego, o Córrego do Capim, e expandiu antingindo a área deste presente estudo.

Atualmente é possível observar que a cidade apresenta uma série de problemas relacionados a ocupação em áreas de fundos de vale e vertentes com declividades acentuadas, pois o processo de ocupação se iniciou nas áreas de fundo de vale, exatamente nas margens do Córrego do Capim, e foi se expandindo para as vertentes e topos das colinas suavemente onduladas. (COSTA; PEDRO MIYAZAKI, 2015, p. 52) 
O processo de ocupação urbana associado às morfologias do relevo tende a contribuir de forma efetiva para a aceleração de eventos considerados naturais, como as enchentes, inundações alagamentos. As enchentes e inundações tendem a ocorrer associados às áreas de fundo de vale, já os alagamentos ocorrem em áreas de depressão no relevo o que dificulta o escoamento da água.

Diante disso, o estudo teve como objetivo principal analisar a relação entre a ocupação do relevo e os episódios de alagamentos que ocorrem na cidade de Capinópolis/MG.

$\mathrm{Na}$ área urbana do municipio de Capinópolis/MG foi possível observar a ocorrência de alagamentos em áreas de topo do relevo, sendo este relevo formado principalmente por colinas com topos suavemente ondulados.

\section{Discussão Teórica}

A relação entre ocupação do relevo e os episódios de alagamentos tende a ganhar destaque na medida em que as cidades passam a expandir sua malha urbana, se apropriando de compartimentos com processos dinâmicos específico, entrando em desequilíbrio a partir do momento em que novas características são adicionadas as formas de relevo, como a impermeabilização das vertentes.

Entende-se que a esculturação do relevo demanda tempo, e as características destas formas serão definidas de acordo com o clima, a formação rochosa, a cobertura vegetal assim como o sistema fluvial. Estes fatores tentem a atuar de forma conjunta, promovendo a esculturação destas morfologias. Diante disso:

Os processos morfogenéticos são os responsáveis pela esculturação das formas de relevo, representando a ação da dinâmica externa sobre as vertentes. Esses processos não agem separadamente, mas em conjunto, no qual a composição qualitativa e a intensidade dos fatores respectivos são diferentes. (CHRISTOFOLETTI, 1980, p. 27)

Essas formas são então, resultados de processos que esculpiram o relevo, ocorrendo por meio de "ações regulares e contínuas que se desenvolvem de maneira relativamente bem especificada e levando a um resultado determinado" (CHRISTOFOLETTI, 1980, p. 1), cada forma do relevo é resultado de processos agindo sobre o espaço durante um determinado recorte temporal. Dentre as formas têm-se as áreas de topo, as vertentes e os fundos de vale, que passam a ser ocupados e transformados a partir do momento em que o homem é inserido na paisagem como agente transformador.

A vertente, conforme Tricart (1957 apud CASSETI, 1991, p. 35),

[...] constitui o elemento dominante do relevo na maior parte das regiões, apresentandose portanto, como forma de relevo mais importante para o homem. Tanto a agricultura quanto os demais trabalhos de construções, por exemplo, estão interessados na evolução das vertentes que acabam comandando, por exemplo, a perenidade - direta e indireta dos cursos d'água, pela ação geomorfológica. 


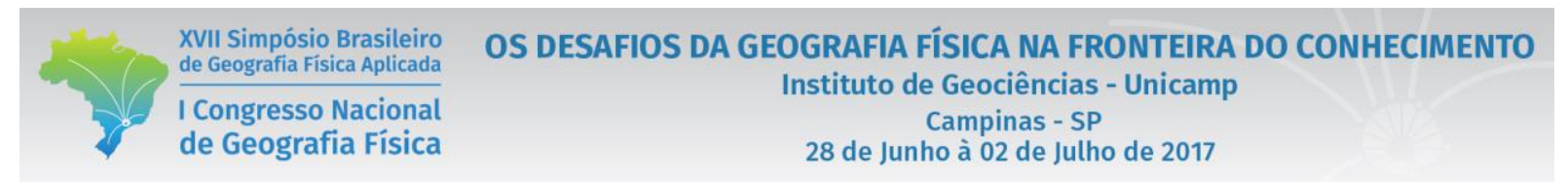

São as vertentes um dos objetos mais importantes e complexos da Geomorfologia, partindo do pressuposto que são nelas que ocorrem os processos tanto morfogenéticos, quanto pedogenéticos, tornando-se complexo delimitar e caracterizar uma vertente de acordo com conceitos pré-estabelecidos. A vertente pode apresentar ainda diferentes morfologias de acordo com as dinâmicas que contribuíram para sua formação, podendo ser lineares, côncavas ou convexas. Entretanto, é raro encontrar somente uma destas morfologias, sendo o mais comum a combinação destas formas ao longo da extensão da vertente.

Outro compartimento que aqui ganhará destaque são os fundos de vale, compartimento este que passou a ser ocupado de forma desordenada nas áreas urbanas, provocando uma série de problemas que posteriormente será destacada.

De acordo com Afini Junior (s.d., p. 37), fundos de vale podem ser considerados, como:

Faixas lindeiras aos cursos de água desenvolvendo-se em planícies ou várzeas, inundáveis ou não nas estações chuvosas, perene ou seco nas estações de estiagens, quase sempre de propriedade privada, mas passíveis de desapropriação por interesse público.

Os fundos de vale são por vezes confundidos com as planícies de inundação, tendo em vista que estas são partes de altitude mais baixa e que durante as cheias são ocupadas temporariamente pelo canal fluvial. Ocorre então que na maioria das áreas urbanas estes compartimentos tendam a ser transformandos durante o processo de ocupação do relevo, muitas vezes suprimindo algumas das características principais dessas morfologias.

Um dos primeiros passos destes agentes é transformar o espaço para que ele se torne habitável para uma determinada população, de encontro a este pensamento vem Pedro Miyazaki (2014), ao enfatizar o papel dos agentes e principalmente apontar que estas modificações realizadas tendem a causar impactos e alterações nas dinâmicas naturais. Assim,

As alterações nas formas de relevo são bastante frequentes no ambiente urbano, isso decorre da dinâmica de produção do espaço urbano. Os agentes responsáveis pela produção desse espaço apropriam-se dos compartimentos geomorfológicos, sejam eles topos, vertentes ou fundos de vale, realizam a retirada da cobertura vegetal, fazem obras de terraplanagem que envolvem cortes e aterros nas vertentes. Essa dinâmica de ocupação remodela os compartimentos do relevo e aceleram os processos responsáveis pela sua esculturação, provoca também alterações nos fluxos, sejam eles de águas (pluviais, servidas, fluviais), ou de sedimentos (terra). (PEDRO MIYAZAKI, 2014, p. 77)

Levando em consideração as alterações provocadas no relevo e o equilibrio dinâmico dos processos naturais que passam a ser alterados, serão levantados os problemas ou desastres causados durante períodos chuvosos, que são as enchentes, inundações e alagamentos, sendo esse último o foco principal do estudo. O Ministério das Cidades/IPT (2007) classificou esses eventos de acordo com a ocorrência de cada um, sendo: as enchentes a elevação do nível d'agua do canal fluvial durante um espaço de tempo devido à 
concentração de água no mesmo; a inundação como extravasamento das águas de um canal para as margens, ocasionada quando a enchente atinge acima da cota máxima e extravasa a calha principal do rio; já os alagamentos não necessariamente estão ligados à dinâmica fluvial, mas sim à pluvial sendo o acúmulo momentâneo de água num determinado ponto, ocasionado pela insuficiência do sistema de drenagem urbana.

Procurando ilustrar os processos de enchente, inundação e alagamento, utilizou-se a figura abaixo (figura 02), que representa de forma clara a dinâmica do curso d'água durante os períodos de chuva, assim como o que ocorre a partir do momento em que as planícies de inundação passam a ser ocupadas.

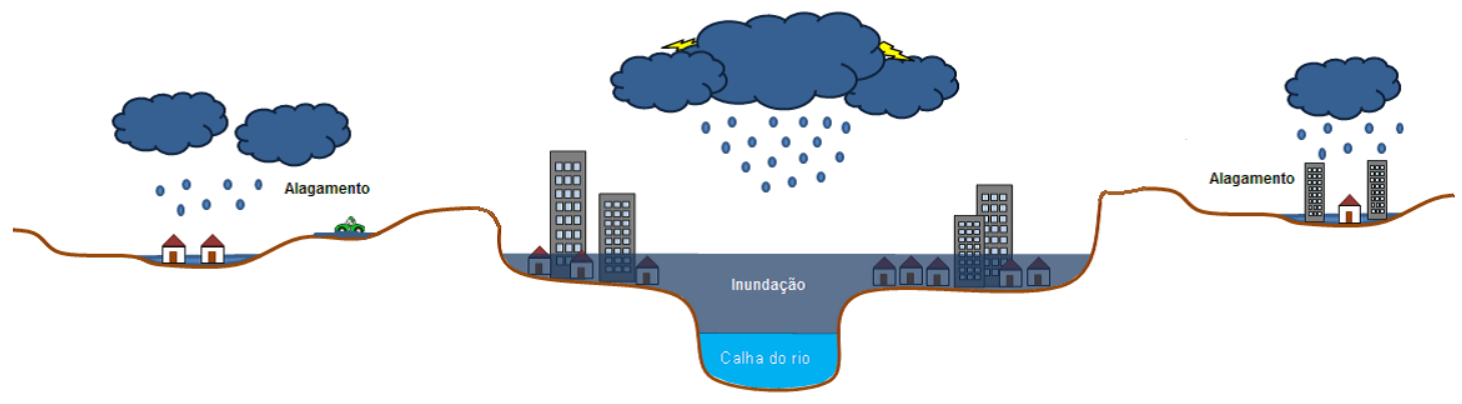

Figura 02: Inundação e alagamento. Fonte: http://aquafluxus.com.br/?p=4997

Os alagamentos vêm se tornando cada dia mais comuns, principalmente nas cidades, evento que se justifica por conta da forma de apropriação e ocupação do relevo, como consequência da impermeabilização do solo e concentração de fluxos num determinado ponto atrelados à ineficiência do sistema de drenagem urbana.

Nas cidades, a questão da drenagem urbana envolve, além dos processos hidrológicos de enchentes e inundações diretamente ligadas aos cursos d'água naturais, processos de alagamentos e enxurradas, decorrentes de deficiências no sistema de drenagem urbana e que podem ou não ter relação com os processos de natureza fluvial. Em muitas cidades o descompasso entre o crescimento urbano e a drenagem urbana tem originado graves problemas de alagamentos e enxurradas. (Min. Cidades/IPT, 2007, p. 97)

Seguindo a ideia apresentada pelo Ministério das Cidades, Castro (2003) acrescenta o fato de que estes alagamentos tornam-se ainda mais frequentes em cidades cujo planejamento foi mal elaborado, ou ainda em cidades que o crescimento ocorreu de forma explosiva dificultando as obras de drenagem e esgotamento de águas pluviais. Destaca-se então que ao contrário das enchentes e inundações, os alagamentos não possuem ligação direta com as dinâmicas do canal fluvial, sendo que:

[...] caracterizam-se por não estarem ligados às drenagens (como as enchentes e as inundações), sendo decorrentes de uma incapacidade de drenagem das águas de chuva, em razão da topografia muito suavizada, da insuficiência (ou inexistência) dos sistemas de captação de águas pluviais, ou de ambas. Em termos gerais, têm características semelhantes ás das enchentes e inundações localizadas. (Cerri, 1999 apud OLIVEIRA, 2004, p. 21) 
Teodoro e Nunes (2010, p.82) destacam que "os alagamentos ocorrem, geralmente, em áreas planas ou com depressões e fundos de vales, com o escoamento superficial comprometido pela topografia e falta ou insuficiência de um sistema pluvial no ambiente urbano". À medida que ocorrem períodos chuvosos por um determinado espaço de tempo, tem-se o acúmulo momentâneo de água, nesses casos não ocorre nem a infiltração nem mesmo o escoamento da água. Desta forma a água fica contida em determinados pontos incapazes de ser drenada e muitas vezes são áreas ocupadas, o que provoca uma série de transtornos à população que ali reside.

Fato é que, homem e natureza encontram-se hoje numa disputa de forças, na qual o homem impõe suas necessidades e a natureza direta ou indiretamente responde por meio de eventos como os alagamentos.

A dinâmica natural e a ação antrópica deveriam coexistir de forma integrada e enquadrar-se numa perspectiva de equilíbrio dinâmico, até porque é preciso notar que o Homem, um ser natural, não é um fator externo ou alheio à orgânica dos ecossistemas. Contudo, a sua intervenção tem causado a ruptura do equilíbrio ambiental existente, influenciando a ocorrência de processos morfogenéticos ou emergindo como principal fator desencadeante desses processos. (PEDROSA, 2012, p. 13)

Assim tem-se o homem e suas intervenções no espaço como um dos principais responsáveis pela aceleração destes eventos, tendo em vista seu poder de transformação no espaço. A alteração nas dinâmicas naturais faz com que novas dinâmicas se instalem e por vezes passam a gerar impactos tanto sobre o meio ambiente quanto para o homem em si, ao ser afetado por eventos como enchentes, inundações e alagamentos.

\section{Resultados}

Levando em consideração as dinâmicas da natureza, principalmente no que tange as dinâmicas pluviais, e ainda as intervenções realizadas pelo homem é possível notar a quantidade de eventos relacionados às enchentes, inundações e alagamentos aumentando e sendo constantemente divulgados nos meios de comunicação.

O município de Capinópolis/MG tem seu relevo configurado em colinas convexizadas, possuindo topos amplos e suavemente ondulado, as vertentes dividem em convexas, concavas e retilíneas. Com relação aos fundos de vale é possível tanto encontrar córregos mais encaixados em fundo de vale em $\mathrm{V}$ quanto em berço.

É interessante ressaltar que o processo de ocupação do relevo em Capinópolis/MG seguiu a lógica da maioria dos centros urbanos, que é a ocupação de áreas próximas dos canais fluviais, assim, tem-se inicialmente a ocupação das áreas de fundo de vale de dois dos três córregos que se encontram no 
perímetro urbano do município, o Córrego do Capim e o Córrego Olaria. O entorno deste último córrego tornou-se o principal objeto de análise deste estudo, tendo em vista que as alterações da morfologia do córrego e do relevo permitiram considerá-lo como área de risco a alagamentos, sendo que em determinados locais o período de cheia do canal fez com que inundasse as margens do mesmo.

Os processos naturais de formação e transformação do relevo possuem sua própria dinâmica, ao inserir o homem como agente transformador há uma ruptura nessa dinâmica, assim, processos como escoamento e infiltração passam a ser alterados. Nas áreas urbanas, a tendência durante o processo de ocupação é que a vegetação seja retirada e em seu lugar surjam às construções urbanas, essa modificação faz com que seja impermeabilizado, altera-se então a dinâmica de infiltração da água no solo. Por consequência, a água que não infiltra tende a escoar, este escoamento superficial torna-se um problema nas áreas urbanas a partir do momento em que se associam a uma rede de drenagem incapaz de fazer com que a água passe pela cidade sem grandes impactos, surgem aí os alagamentos, as enchentes dos canais fluviais e em alguns casos a inundação desse canal.

A partir daqui serão expostos alguns eventos ocorridos relacionado aos alagamentos, buscando apontar uma ligação entre o evento, as formas do relevo e o tipo de ocupação realizado durante a expansão da malha urbana.

Ao adotar a área urbana de Capinópolis/MG como objeto de estudo e relacioná-la a tais eventos é possível encontrar uma série de reportagens nas mídias eletrônicas sobre os alagamentos e seus impactos e por meio de depoimentos de moradores. Neste sentido, foi realizado um levantamento dessas reportagens para comparar com os dados diários obtidos no INMET e verificar a quantidade de precipitação necessária para provocar alagamentos na área urbana de Capinópolis. Os dados foram coletados do Banco de Dados Meteorológicos para Ensino e Pesquisa (BDMEP) no site do INMET, foram utilizados os dados históricos dos meses mais expressivos sendo março e novembro de 2014 e novembro de 2015. A estação utilizada foi a de Capinópolis/MG (83514), latitude $-18.71^{\circ} \mathrm{S}$ e longitude $-49.55^{\circ} \mathrm{W}$ e altitude de 620,60 metros, que teve o início de suas operações em 1989.

O primeiro evento relacionado às dinâmicas pluviais e se configura como alagamento, foi identificado num área de topo suavemente ondulado, onde recentemente foram construídos dois conjuntos habitacionais, o bairro recebeu o nome de Roney de Almeida Garcia. No mês de março de 2014, ocorreu no bairro Roney de Almeida Garcia o alagamento de uma de suas vias de acesso, chegando a cobrir o calçamento. Desde a inauguração o bairro têm algumas de suas vias alagadas, tendo em vista a configuração do relevo, entende-se que áreas de topo suavemente onduladas tendem a possuir em determinados pontos pequenas depressões, o que é o caso deste bairro, ele se situa sobre uma pequena depressão. Ao associar essa depressão na área de topo e o sistema de drenagem que é insuficiente para 


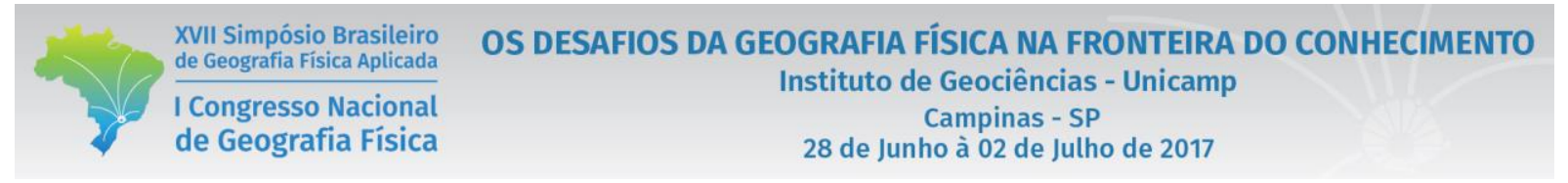

captar e escoar a água tem-se o acúmulo momentâneo da água da chuva nas partes mais baixas, se configurando em alagamento.

O evento ocorreu no dia 22 de março de 2014, que consequentemente é um dos dias com a maior incidência de precipitação na cidade de Capinópolis/MG (figura 03), o que associado à disposição das ruas, tipo de relevo e sistema de drenagem, fez com que a água fosse acumulada momentaneamente na via de acesso localizada na parte mais baixa do bairro.

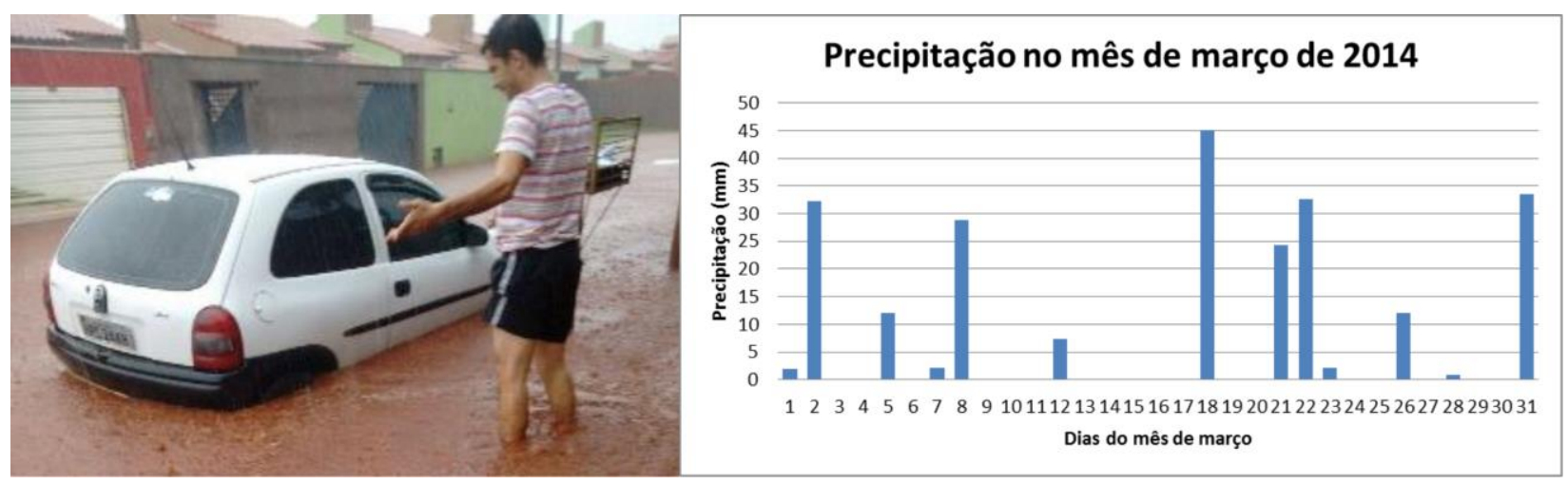

Figura 03: Alagamento no Bairro Roney de Almeida Garcia/Precipitação no mês de março de 2014. Fonte: ARAÚJO, D., 2014; INMET, 2017; Org.: COSTA, H. R. O., 2017.

Os alagamentos no bairro se tornaram recorrentes no ano de 2014, sendo relatado por alguns moradores que durante chuvas fortes o sistema de drenagem ficava sobrecarregado e entrava nas casas por meio dos ralos. A Prefeitura Municipal realizou uma série de obras, inclusive a construção de uma galeria para escoar o excedente de água, no entanto o bairro ainda registra casos de alagamentos, porém, em menor frequência.

No mesmo ano, ocorreu no mês de novembro o alagamento de uma das principais vias de acesso da cidade, a Avenida 101 localizada na parte central da cidade, evento que foi noticiado pelo jornal "Tudo em Dia" com a reportagem "Chuvas fortes causaram estragos em Capinópolis - Avenida 101 ficou alagada". A avenida encontra-se no fundo de vale do Córrego Olaria, por consequência concentra os fluxos de água da chuva advindos das vertentes no entorno, sabendo que é um ponto de concentração dos fluxos o sistema de captação das águas pluviais deveria ser capaz de escoar tal contingente, no entanto é insuficiente. As chuvas que se iniciaram no dia 4 e continuaram no dia 5 de novembro de 2014, fizeram com que a Avenida 101 fosse alagada momentaneamente, é possível notar que o dia 5 é o dia com maior concentração de precipitação no mês de novembro (figura 04). 


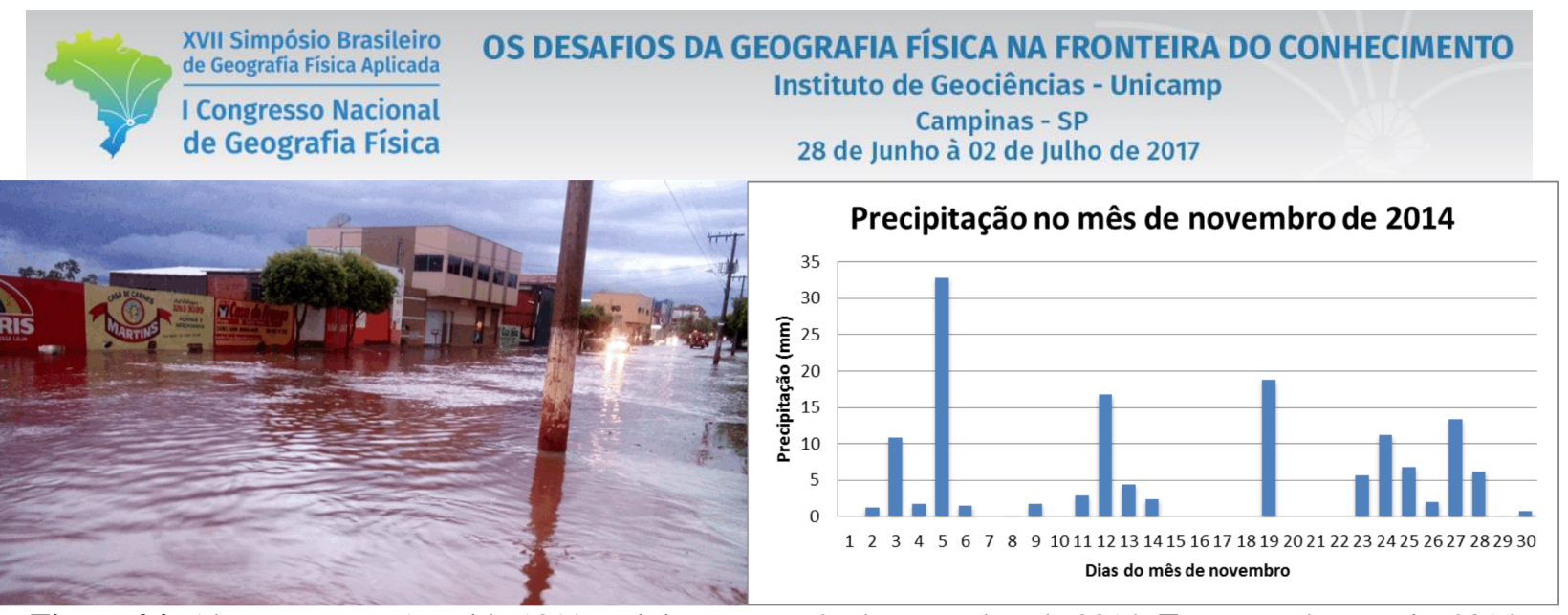

Figura 04: Alagamento na Avenida 101/Precipitação no mês de novembro de 2014. Fonte: Tudo em Dia, 2014; INMET, 2017; Org.: COSTA, H. R. O., 2017.

Esse ponto retrata dois problemas gerados pela apropriação do relevo, num primeiro momento a ocupação do fundo de vale, área que ao levar em consideração os processos naturais é considerada frágil e passa a ser mais afetada quando se relaciona com o segundo problema, a impermeabilização das vertentes. Ao impermeabilizar a vertente o solo perde a capacidade de absorver a água das chuvas, por consequência essa água tende a escoar superficialmente e se concentrar na parte mais baixa do relevo, o fundo de vale, nesse ponto, também impermeabilizado a água se acumula momentaneamente.

Sabe-se que cada vertente possui características como a dispersão de água e a concentração de água, no caso das vertentes que se ligam ao fundo de vale do Córrego Olaria e principalmente ao ponto de alagamento em questão, tem-se a presença de vertentes convexas e retilíneas o que prioriza a dispersão de água. Associando a morfologia do relevo e o processo de ocupação que resultou na impermeabilização das vertentes, é possível afirmar que durante períodos de chuva a quantidade de água destinada ao fundo de vale é maior do que a sua capacidade de escoar, tendo em vista que o fundo de vale, no ponto, também encontra-se impermeabilizado a área torna-se de risco à alagamentos, por ser incapaz de escoar a água que lhe é destinada.

Cabe ressaltar que o córrego Olaria tem uma parte canalizada e passa por baixo dessa avenida, o problema nessa área é recorrente, tendo em vista que em 2009 foi registrado o colapso dessa canalização e nos anos de 2014 e 2015 foram registrados casos de alagamento nessa área.

Eventos como alagamentos tornam-se comuns em áreas de fundo de vale, quando impermeabilizados. Numa dinâmica dos processos dita equilibrada, a água da chuva antinge o solo e se divide, parte dela infiltra no solo alimentando reservatórios de água e parte dela escoa e atinge o canal fluvial. O processo de ocupação do relevo faz com que essa dinâmica entre em desequilíbrio, a retirada da vegetação, modificação das formas de relevo e impermeabilização do solo, faz com que a água que antes infiltrava passe a escoar, sendo destinada aos fundos de vale, no caso de fundos de vale abertos a tendência é que este canal passasse por uma cheia repentina, ou seja, ocorresse uma enchente e em alguns casos 
inundações. No entanto, no caso de Capinópolis o fundo de vale foi canalizado e encontra-se impermeabilizado, priorizando eventos como os alagamentos.

O Jornal "Tudo em Dia" divulgou no dia 26 de novembro a manchete "Chuva forte causa estragos em Capinópolis", entre os impactos da chuva a Avenida 101 voltou a ser alagada no dia 25 novembro de 2015, em consequência da insuficiência no sistema de captação e drenagem das águas pluviais. Ressaltase aqui a ocorrência do evento na mesma área em dois anos consecutivos durante o mês de novembro. A ocorrência desse evento pode ser comprovada e justificada por meio dos dados de precipitação coletados no mês de novembro de 2015, no qual o dia 25 registrou um dos maiores números referentes à chuva (figura 05).

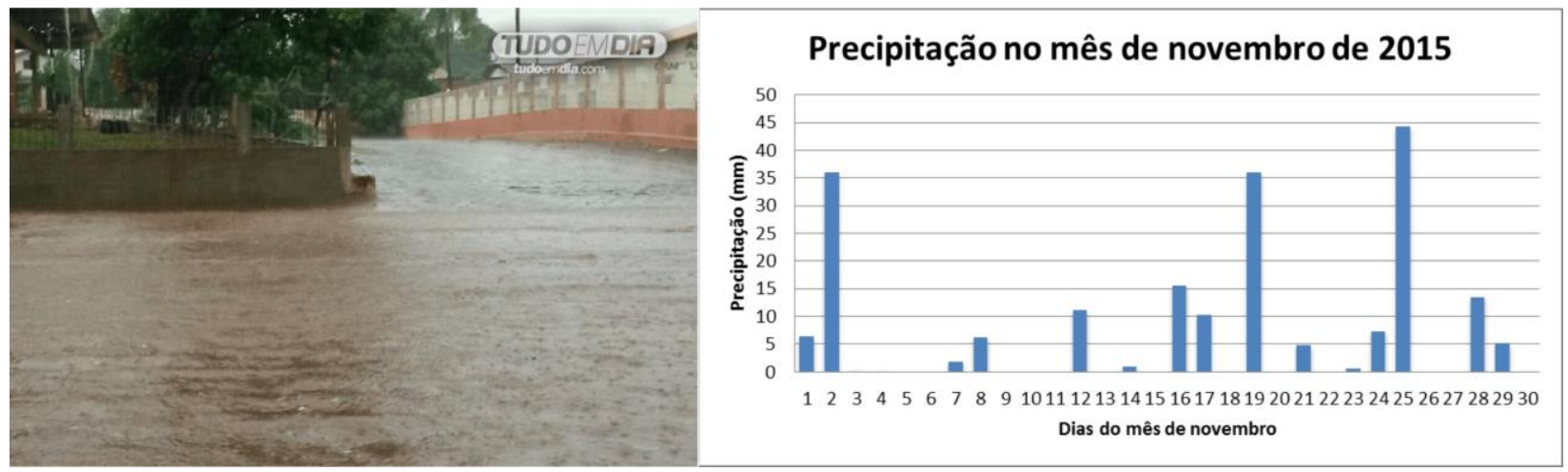

Figura 05: Alagamento na Avenida 101/Precipitação no mês de novembro de 2015. Fonte: Tudo em Dia, 2014; INMET, 2017; Org.: COSTA, H. R. O., 2017.

A cidade de Capinópolis/MG com cerca de dezesseis mil habitantes é considerada como uma cidade pequena, em processo de desenvolvimento, o que torna estes eventos ainda mais preocupantes. O processo de ocupação do relevo na cidade vem sendo realizado sem levar em consideração os processos dinâmico, criando desequilíbrios, uma série de eventos passaram a ser noticiados nos últimos anos o que permite compreender que a cidade possui áreas de risco a alagamentos, em determinados pontos é possível também identificar áreas onde as enchentes e inundações ocorrem nos períodos mais chuvosos. A combinação das formas de relevo, contingente hídrico e insuficiência no sistema de drenagem fez com que a água acumulasse na parte mais baixa do relevo, o que provoca transtorno tanto para os moradores quanto para a administração da cidade, sem levar em conta os impactos ambientais e sociais por trás dos alagamentos.

\section{Considerações Finais}

As formas do relevo associadas ao processo de ocupação em áreas urbanas têm se tornado foco de uma série de estudos, principalmente no que tange as áreas de risco. Os alagamentos registrados em 
Capinópolis/MG ressaltam que estes problemas não são identifidados apenas em grandes centros urbanos, o que traz validade e importância para o estudo de áreas de risco à alagamentos em cidades pequenas.

Devido ao adensamento da malha urbana, concentrando sua ocupação nas áreas de fundo de vale, os alagamentos tornaram-se cada vez mais presentes na realidade urbana da cidade de Capinópolis/MG. Ressaltando o fato de que os fundos de vale foram os primeiros a ser ocupados na cidade é passivel de se chegar à conclusão de que as técnicas utilizadas para a ocupação daquelas áreas eram rudimentares se comparadas às técnicas existentes atualmente. Assim, ao relacionar o compartimento geomorfológico dos fundos de vale com a forma como este foi ocupado, é possivel identificar uma série de problemas como a incapacidade do sistema de drenagem urbana, não conseguindo escoar o flúxo de água fornecido durante períodos chuvosos.

Além dos fundos de vale, as vertentes e áreas de topo foram sendo apropriadas e ocupadas a partir do momento em que a expansão da malha urbana tornou-se uma necessidade para a cidade de Capinópolis/MG abrigar seus moradores. A partir daí teve-se o rompimento do equilibrio dinâmico dos processos naturais, a impermeabilização do relevo impossibilitou que a água das chuvas infiltrasse, priorizando o escoamento superficial, direcionando para os fundos de vale incapazes de dispersar o contingente de água.

Em qualquer instância de ocupação urbana, a preocupação em relacionar as formas de relevo, o tipo de ocupação e o equilibrio dinâmico dos processos naturais são essenciais, tendo em vista que existem formas de se apropriar do relevo sem que os impactos sejam tão caóticos. Os estudos voltados para a prevenção, gestão e planejamento relacionados às áreas de risco devem se tornar uma das prioridades do poder público, tendo em vista de que os gastos destinados à prevenção e gerenciamento tendem a ser menores que os gastos com a mitigação de impactos e recuperação de áreas impactadas.

\section{Agradecimentos}

Agradeço ao Grupo de Estudos e Pesquisas em Geomorfologia, Pedologia e Dinâmicas Ambientais (GEPDA) e Laboratório de Ensino e Pesquisa em Pedologia, Geomorfologia e Ensino de Geografia Física (PEDOGEO) pelo apoio e suporte para pesquida. A FAPEMIG por ter contribuido com o apoio na divulgação de parte desta pesquisa. A CAPES por contribuir financeiramente para a realização desta pesquisa.

\section{Bibliografia}

AFINI JUNIOR, B. Fundos de Vale. Disponível em: < http://www.revistadae.com.br/artigos/artigo_edicao_90_n_528.pdf>. Acesso em: 23 de março de 2014. 


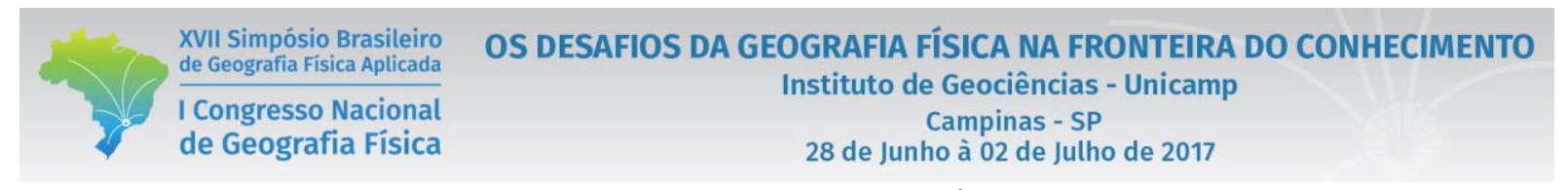

BRAGA, Paulo. Chuva forte causa estragos em Capinópolis. Tudo em dia. Disponível em: <http://www.tudoemdia.com/2015/11/chuva-forte-causa-estragos-em-capinopolis>. Acesso em: 17 dez. 2016.

BRAGA, Paulo. Chuvas fortes causaram estragos em Capinópolis: Avenida 101 ficou alagada. Tudo em dia. Disponível em: <http://www.tudoemdia.com/2014/11/chuvas-fortes-causaram-estragos-em-capinopolis-avenida-101ficou-alagada>. Acesso em: 17 dez. 2016.

BRAGA, Paulo. Enxurrada de água e lama invade casas na "Chácara Balaieiros" em Capinópolis. Tudo em dia. Disponível em: <http://www.tudoemdia.com/2015/11/enxurrada-de-agua-e-lama-invade-casas-na-chacarabalaieiros-em-capinopolis>. Acesso em: 17 dez. 2016.

CASSETI, Valter. Ambiente e Apropriação do Relevo. São Paulo: Editora Contexto, 1991. 84p.

CASTRO, A.L.C. Manual de desastres: desastres naturais, Brasília, Ministério da Integração Nacional, 2003. 182p

CHRISTOFOLETTI, A. Introdução à Geomorfologia. In: CHRISTOFOLETTI, A. Geomorfologia. $2^{\mathrm{a}}$ ed. São Paulo: Edgard Blucher, 1980. p. 1-25.

CHRISTOFOLETTI, A. Vertentes: processos e formas. In: CHRISTOFOLETTI, A. Geomorfologia. $2^{\mathrm{a}}$ ed. São Paulo: Edgard Blucher, 1980. p. 25-64.

COSTA, H. R. O. PEDRO MIYAZAKI, L. C. Análise preliminar dos dados pluviométricos e caracterização das áreas de risco à enchente, inundação e alagamento na cidade de Capinópolis/MG. Boletim de Geografia, Maringá, v. 33, n. 3, p. 46-67, set.-dez., 2015

MINISTÉRIO DAS CIDADES/INSTITUTO DE PESQUISAS TECNOLÓGICAS - IPT - Mapeamento de riscos em encostas e margens de rios. Brasília: Ministério das Cidades; Instituto de Pesquisas Tecnológicas - IPT, 2007. $176 \mathrm{p}$.

OLIVEIRA, E. L. A. Áreas de Risco Geomorfológico na Bacia Hidrográfica do Arroio Cadena, Santa Maria/RS: zoneamento e hierarquização. 2004. 147 f. Dissertação (Mestrado em Geografia) - Instituto de Geociências, Universidade Federal do Rio Grande do Sul, Porto Alegre, 2004.

PEDRO MIYAZAKI, L. C. Dinâmicas de apropriação e ocupação em diferentes formas de relevo: impactos e vulnerabilidades em ambientes urbanos. 2014. 265 f. Tese (Doutorado em Geografia) - Universidade Estadual Paulista, Faculdade de Ciências e Tecnologia, Presidente Prudente. 2014

PEDROSA, A. S. O Geógrafo como técnico fundamental no processo de gestão dos riscos naturais. Boletim Goiano de Geografia, Goiânia, v. 32, n. 1, p. 11-30, jan./jun. 2012.

TEODORO, P. H. M.; NUNES, J. O. R. Os Alagamentos em Presidente Prudente-SP: um Trabalho Interdisciplinar Embasado no Mapeamento Geomorfológico. Revista Formação, n.17, volume 2, 2010 , p. 81-102. 